\title{
João Ternura e o Rio de Janeiro: o homem perdido da/na cidade
}

\author{
Luiza Vilma Pires Vale*
}

\begin{abstract}
Resumo: Este artigo analisa a trajetória de João Ternura, personagem principal do romance João Ternura, de Aníbal Machado, no Rio de Janeiro, mostrando sua falta adaptação ao modo de vida da grande metrópole. Embora o protagonista procure integrar-se ao cotidiano da cidade, ele sempre vai sentir-se um estrangeiro, pois não consegue entender o código que norteia as relações dos homens das grandes centros urbanos. Sua vida é marcada por tentativas constantes de integrar-se à cidade, que se frustram e acentuam a impossibilidade de ele estabelecer uma relação harmônica com o ambiente metropolitano.
\end{abstract}

Palavras-chave: Metrópole; estrangeiro; João Ternura; código citadino.

\begin{abstract}
This paper analyses the trajectory of João Ternura, the main character of the novel João Ternura by Anibal Machado, in Rio de Janeiro, demonstrating his lack of adjustment to the city way of life. Despite his attempt to be integrated to the city everyday routine, he feels an outsider all the time, because he cannot understand the code that rules the relationships among people in large urban centers. His life is marked by constant attempts to become an integral part of the city, which are frustrated and stress his impossibility to establish a suitable relationship with the urban environment.
\end{abstract}

Keywords: Metropolis; foreigner; João Ternura; urban code.

Entrava, saía, voltava, saía de novo. À procura de quê, não sabia. As coisas perdiam a consistência, fugiam. Ninguém lhe dava atenção, ninguém dava atenção a ninguém. Sentia-se à margem, como nos primeiros tempos depois da chegada. Excluído de tudo, excluído mesmo do mundo físico, tinha a sensação de que perdera o contato com as raízes do universo. Não mais corpo químico, espírito ou o que fosse a circular na atmosfera. Olhou para o Rio de Janeiro com a mágoa de amante desprezado. Pela primeira vez pensou na morte. $(\mathrm{JT}, 140-1)^{1}$

O objetivo deste artigo é apresentar a análise da trajetória de João Ternura, protagonista da obra homônima, de Aníbal Machado, na cidade do Rio de Janeiro. Pretende-se mostrar, conforme sintetiza a epígrafe, que a personagem vive à margem da sociedade à qual deveria pertencer; que, mesmo agindo como alguém em busca de algo que o leve a identificar-se com o cotidiano do lugar e a integrar-se com as pessoas, vai transitar pela cidade como um estrangeiro. Nessa condição, vê-se que ele tem poucos amigos, e suas relações com os companheiros não são duradouras. No plano afetivo, mantém relação instável com Rita, de

\footnotetext{
* Doutoranda UFRGS.

1 As citações constantes no trabalho são extraídas do exemplar MACHADO, Aníbal. João Ternura. Rio de Janeiro: José Olympio, 2004. Para facilitar, após as transcrições, são colocadas as inicias JT, seguidas do(s) número(s) da(s) página(s).
} 
quem sempre está à procura, já que ela aparece e desaparece de sua vida. A tentativa de resumir-se o cotidiano da personagem na grande metrópole revela a série de choques e rupturas que ocorrem no seu dia-a-dia, comprovando a idéia que se pretende apresentar de que João Ternura, na grande metrópole, parece estar sempre fora do lugar, situação semelhante à do homem que vive nas grandes metrópoles. A forma de ele definir-se como "em preparativos" (JT, p. 203) parece reforçar sua condição de estrangeiro na cidade.

Antes da análise, para situar melhor a obra como um todo, pretende-se apresentar algumas considerações sobre a construção do romance homônimo.

\section{Construção de João Ternura}

O romance João Ternura, de Aníbal Machado, embora o autor tenha começado a escrevê-lo em 1926, só foi publicado postumamente, em 1965, graças à intervenção de Carlos Drummond de Andrade, que se encarregou de organizar "dois textos datilografados, nos quais se inseriram algumas páginas sem manuscritos”, conforme nota constante na primeira edição da obra. $\mathrm{O}$ fato de o autor tê-lo gestado durante muitos anos, apenas referindo-se à sua criação e publicando pequenos trechos, suscitou muita expectativa entre seus amigos e leitores, conforme se percebe no depoimento do crítico Otto Maria Carpeaux, logo após a publicação de João Ternura:

Quando conheci Aníbal - parece-me que foi em 1941 - me diziam os amigos: os contos são ótimos, muita outra coisa ótima está escondida nas gavetas, mas Aníbal ainda não tem dado toda a medida do seu talento; espere o João Ternura. Eles próprios já esperavam então, há anos esse João Ternura que já estaria escrito mas ainda não definitivamente redigido, ou então, estaria mentalmente pronto no espírito do seu criador mas ainda não escrito, ou então, teria ficado fragmento e ficaria fragmento para sempre. Enfim, João Ternura virou uma grande lenda da literatura brasileira: meio boato e meio símbolo. Mas agora João Ternura está aqui, entre nós, pronto e perfeito. (CARPEAUX, apud CUNHA, 1974, p. 136)

O escritor e crítico Renard Perez, referindo-se à origem de João Ternura, afirma:

Em 1926 (morava na Tijuca), baseado em episódios de infância e nas lembranças de Sabará, iniciou o famoso romance João Ternura, Lírico e Vulgar. Escreveu o livro até 1932, com pausas, mostrando-o aos mais íntimos quando afinal o suspendeu, um tanto intimidado pelo trombeteamento dos amigos em torno da obra. [...] O excesso de elogios, tratando-se de um livro ainda incompleto (de que os leitores só conheciam trechos publicados em revista), preocupou de tal modo o escritor a ponto de abandoná-lo. Por cerca de vinte e quatro anos permaneceram os originais engavetados; pela altura de 1956, entretanto, resolveu Aníbal exumá-los, neles recomeçando a trabalhar, embora lentamente. (PEREZ, apud CUNHA, 1974, p. 136)

Aníbal Machado publicou alguns fragmentos do romance durante o período de sua criação, como, por exemplo, o trecho EMBOLADA DO CRESCIMENTO (o uso da letra maiúscula é do autor), que faz parte do Livro I de João Ternura foi editado anteriormente na revista "Acadêmica", em 1937. A versão inicial foi modificada ao integrar-se à obra, 
principalmente no aspecto formal relativo à pontuação, pois o texto que aparece na obra só é pontuado no final, conforme se pode observar a seguir:

Enquanto a criança crescia a mãe arrumava a casa, esperava o marido, dormia, ia à igreja, conversava, dormia outra vez, regava as plantas, arrumava a casa, fazia compras, acabava as costuras, enquanto a criança crescia e as tias chegavam à janela, olhavam o tempo, extendiam [sic] os tapetes, imaginavam o casamento, ralavam o coco, liam os crimes e os dias iam passando enquanto a criança dormia e crescia pois o tempo parou para esperar que a criança crescesse. (MACHADO, apud ANTELO, 1984, p.158)

EMBOLADA DO CRESCIMENTO - Enquanto a criança crescia a mãe arrumava a casa esperava o marido dormia ia à igreja conversava dormia outra vez regava as plantas arrumava a casa fazia compras acabava as costuras enquanto a criança crescia as tias chegavam à janela olhavam o tempo estendiam os tapetes imaginavam o casamento ralavam o coco liam os crimes e os dias iam passando enquanto a criança dormia crescia pois o tempo parou para esperar que a criança crescesse. (JT, p. 38)

No livro Cadernos de João, publicado em 1957, obra em que Aníbal Machado apresenta pequenas histórias, reflexões suas sobre o mundo, notas e poemas, percebe-se que o fragmento "Homem em preparativos" descreve a personagem central do romance, expondo idéias sobre o sentido de sua existência e o do tempo, como se pode ver nas citações a seguir, ao comparar- se um trecho expresso em Cadernos de João com um diálogo de João Ternura com seu amigo Manuel, constante no romance homônimo, nos quais a personagem se diz estar sempre "em preparativos" :

\section{HOMEM EM PREPARATIVOS}

Ando sempre em preparativos.

[...]

Com isso, vou-me distraindo. Troco coisas e idéias. Alguns me ajudam, servem-se também de mim. E todos assim nos distraímos nesses preparativos.

Mas com que seriedade! Com que paixão!

Nos momentos de intervalo, construímos cidade, casamos, discutimos, entramos na guerra.

Preparamo-nos todos para qualquer coisa que ainda não aconteceu. Há dezenas de anos tem sido assim, Há milhares de anos...

$[\ldots]$

Procuro sempre... Procuro sem remitência. Invento novas dificuldades.

Adoro os obstáculos...

Vivo assim amontoando, renovando, corrigindo, experimentando, caindo e me aprumando.

Assim não chegará jamais o dia da minha inauguração. Pois o meu pavor é a viagem concluída, a coisa acabada... (Cadernos de João, p. 57. O uso do itálico é do autor.)

$[\ldots]$

— Já é tempo de levar a vida a sério, Ternura.

- Por acaso estou levando a vida em brincadeira?

- Não sei... você dá a impressão de que ainda não assentou a cabeça... de que continua esperando — ? - Esperando o quê, não sei. Esperando o que não vem, o que não existe...

- Ainda não comecei, Manoel.

— Toda a vida com essa mania de achar que ainda não começou...

- Já te disse que ando sempre em preparativos...

— Engano é pensar que o principal ainda não aconteceu, que a verdadeira vida é outra.

- A verdadeira está longe ainda, Manuel... Apenas pressentida. Às vezes parece que está quase, mas é ilusão.

[...]

— Eu não penso em nada, Manuel. Estou apenas te dizendo que eu ainda não comecei... 
(JT, p. 203-204. Grifo nosso)

Fragmentos que compõem João Ternura podem ser lidos isoladamente nas publicações feitas antes do aparecimento do romance, mas na obra eles articulam-se entre si, tecendo a narrativa que apresenta a história do protagonista. Essa construção revela um romance em que há poucas marcações temporais e ausência de um enredo linear com ações encadeadas para um clímax e um desfecho. A narrativa constrói-se por pequenos capítulos, fragmentos — alguns apresentados por apenas uma frase —, diálogos sem a indicação do emissor e pequenos poemas. O autor usa, na obra em análise, como indicativo de separações dos fragmentos, pequenos sinais gráficos, e há trechos em que ele não faz uso de pontuação, como mostram os exemplos a seguir:

O que ninguém sabe é donde vem esse rio, nem para onde vai. Esse rio é um mistério.

A professora disse que quando é noite aqui, lá no outro lado do mundo é dia. Que idéia! Noite é noite mesmo em toda a parte... com latidos e pirilampos, e essa escuridão enorme que me mete medo...

A professora tem cada uma!... Depois que chega a madrugada, sim: a noite vai-se embora do mundo, e aí então é que vem o dia que não faltou nenhuma vez ainda...

Na casa velha da várzea

tem panela fervendo criança

e uma enxó alisando madeira

De noite a casa velha se mexe

disfarçada em neblina

Sobe a serra

desce o vale

capengando de velhinha

Pensam todos que é vazia

mas ela gira que gira

e em cada volta

joga fora

os moradores...

(JT, p.43. 55 e 56. O uso do itálico é do autor)

Poucos escritores se embrenharam por tantas e diversas áreas da criação quanto Aníbal Machado nesse romance, buscando novo espaço para o fazer literário. A concretização dessa busca é revelada principalmente pela mistura dos gêneros, percebida pela presença da forma poética e pelo lirismo de sua prosa, recursos formais que se evidenciam na construção fragmentada de João Ternura. Antes da publicação do romance, em 1960, Aníbal Machado, referindo-se ao fragmentarismo da obra, afirma:

Não raro os episódios se fragmentam e os personagens se diluem na atmosfera que os cria e determina. O ritmo de duração da narrativa é sugerido por tratamento elíptico mediante o seccionamento dos acontecimentos, os quais, parecendo alheios entre si, unificam-se na mesma direção artística. (MACHADO, apud CUNHA, 1974, p. 137).

A construção narrativa de João Ternura distingue Aníbal Machado de alguns de seus contemporâneos. Na opinião de Fausto Cunha, crítico literário, ela é o ponto culminante da 
ficção do autor. No entanto, ele salienta também que o impacto desse modelo de narração se enfraquece pelo fato de o autor não tê-la publicado anteriormente, pois, quando ocorre seu lançamento, "muito do que ela trazia de novidade e de originalidade se situa irremediavelmente no passado" (CUNHA, 1974, p. 137).

A articulação dos fragmentos de João Ternura se efetiva através das seis partes do romance, que o autor denomina Livro I, II, III, IV, V, VI. Nos dois primeiros livros, é narrada a infância de João Ternura, apresentando seu nascimento, suas brincadeiras com o amigo Isaac na chácara onde viveu com os pais e as tias, a primeira viagem que fez ao Rio de Janeiro juntamente com o pai, a falência dos negócios da família e seu encaminhamento para um internato de padres, de onde foge.

Os livros III, IV, V e VI apresentam a vida do protagonista no Rio de Janeiro. Nessa cidade vai viver em uma pensão, participa involuntariamente de uma revolução, relaciona-se com algumas mulheres, trabalha na gráfica de um amigo, passeia livremente pela cidade, faz poucas amizades e brinca com a morte. Quando os que estão à sua volta pensam que está morto, sobrevive para ofender aqueles que lhe trazem flores, e, quando morre, está sozinho, ninguém percebe seu desaparecimento:

Nesse instante, Ternura desapareceu definitivamente.

Sem nada, sem ninguém que o lembrasse, era como se nunca tivesse existido. (JT, p. 291)

\section{João Ternura: o estrangeiro da/na cidade grande}

Desde pequeno, João Ternura sente-se atraído para o mundo que há fora dos limites da chácara onde vive em uma pequena cidade do interior. Cedo toma consciência de que a harmonia da família e o equilíbrio dos que vivem com ele sob o mesmo teto não lhe satisfazem, porque representam valores insignificantes para o mundo dele: mais amplo e mais rico. O início de sua busca por um mundo maior ocorre quando foge de casa, ainda criança, para conhecer o sítio de Zé Lourenço, vizinho morador distante da chácara dos pais:

Lá no sítio do Zé Lourenço onde eu fui é um lugar bonito, muito melhor do que isto aqui... É longe, longe mesmo.... Eu saí sozinho, andei... andei... mas não tive medo.

[...]

Mamãe, o rio lá pra cima é muito mais bonito e tem uma porção de praias. Quase que eu descobria donde é que vem esse rio [...]. (JT, p. 62-63).

A experiência da fuga faz com que sonhe "em ser levado um dia ao longe maravilhoso, abandonado à correnteza" (JT, P. 98) para conhecer o mundo. A atração pelo desconhecido também é observada pelo fascínio que João Ternura tem pela velha Dona Iaiá, uma conhecida da família que esporadicamente visita a chácara dos pais do menino. Enquanto todos se empolgam por seus modos de falar, suas roupas, adornos extravagantes e 
anacrônicos, o protagonista encanta-se por suas histórias e pelo conhecimento de mundo que demonstra ter:

Me ensina o mundo, anda... — dona Iaiá?! Será possível?...

- Dona Iaiá.

[...]

- Conta uma história pra nós, dona Iaiá.

[...]

- Conta,mais, conta...

A velha sabia de tudo. Tudo lhe acontecera. Devia ter a chave da vida.

— Conta mais... E o mundo? Como é o mundo? É como isso aqui? ... É?...

(JT, p. $70-73$ )

Na idade adulta, seus pais, incentivam-no a ir para o Rio de Janeiro em busca de uma vida melhor, mas é o fascínio de conhecer o mundo que leva João Ternura a abandonar a pacata cidade onde nasceu para ir viver na cidade grande. No entanto, lá ele parece estar sempre fora do lugar: não se adapta à rotina do trabalho, preferindo os serviços esporádicos; torna-se herói de uma revolução que aparece inesperadamente em seu cotidiano, não entendendo que importância pode ter o resgate de uma metralhadora feito por ele quando foi solicitado a lançar os panfletos da revolução — um movimento rebelde que ocorre na cidade na tomado do poder por Getúlio Vargas —, num morro habitado por pobres. Ele parece sentir-se melhor no carnaval, um momento de exceção, festa popular em que as pessoas tornam-se anônimas pelo uso das máscaras e brincam sem censura alguma, mostrando a integração de todos os participantes. A personagem parece sentir-se à vontade nesse ambiente porque a situação contrapõe-se à rotina de seu cotidiano; no entanto ao perceber que logo em seguida tudo volta a ser como era antes da festa, "se deu conta do equívoco. Aquilo era apenas uma data do calendário; e o sentido da vida não depende de nenhuma agitação exterior e concertada, nem das festas que os homens convencionam" (JT, p. 247).

Pode-se dizer que a vida de João Ternura na grande metrópole é marcada por situações paradoxais: de um lado, a solidão, fazendo-o sentir-se um estranho, ou seja, um estrangeiro na maioria dos lugares por onde transita; de outro, o desejo de integrar-se à cidade, de misturarse a seus habitantes, às suas ruas, a seus prédios, tentando descobrir seus segredos para entendê-la: "Cidade insone, cidade cruel!... Maravilhosa ao longe, terrível ao perto. Ele caminhava, caminhava [...]” (JT, p.104). A situação de João Ternura é semelhante à do homem que vive na metrópole moderna, pois como sugere Renato Cordeiro Gomes, no livro Todas as cidade, a cidade, a representação da cidade grande, que se modifica constantemente pelo progresso tecnológico, é como um labirinto. Entretanto, invertendo o mito grego do Minotauro em que atingir o meio é a solução, ele diz que chegar ao centro é marca de dispersão (GOMES, 1994, p. 64). Dessa forma, pode-se concluir que Aníbal Machado, ao 
mostrar a situação estrangeira da personagem, caracteriza, em seu romance, o citadino da modernidade, que é visto como uma presa da/na cidade grande, enredado em sua malhas, tentando achar um lugar para viver plenamente (Cf GOMES, 1994, p. 64).

Há de salientar-se que as transformações das metrópoles são conseqüências do "desabrochar do capitalismo mais radiosos" (BOLLE, 2000, p. 29), que, por seu impacto, desorienta o homem que assiste às modificações. Nesse modelo econômico, nas relações pessoais entre os metropolitanos, o que predomina é o individualismo, que faz com que as pessoas se isolem e ignorem o outro, o que contribui para a solidão dos citadinos. Entretanto, parece que com João Ternura a situação é mais conflitante e angustiante, pois ele vem de fora atraído pelo fascínio que as grandes cidades exercem sobre os interioranos e precisa, portanto, adaptar-se ao novo lugar. Mas esse espaço está sempre em mudança, impedindo-o de entender o que acontece ao seu redor. O lugar torna-se hostil e dificulta a integração do protagonista com o ambiente, fazendo-o sentir um estranho por onde passa. Essa situação reforça a idéia de que o crescimento dos grandes núcleos metropolitanos não corrige a discrepância "entre as enormes possibilidades abertas pelo progresso da técnica - aspirações da modernização - e a falta efetiva de criação de um mundo melhor" (BOLLE, 2000, p. 24). A chegada da personagem ao Rio de Janeiro já evidencia a marca do estrangeirismo que caracteriza sua trajetória naquele espaço:

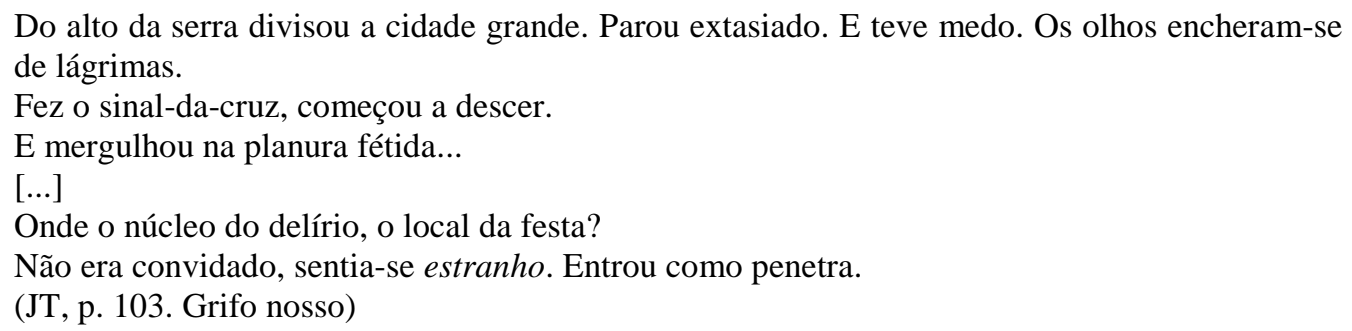
de lágrimas.

Fez o sinal-da-cruz, começou a descer.

E mergulhou na planura fétida...

$[\ldots]$

Onde o núcleo do delírio, o local da festa?

Não era convidado, sentia-se estranho. Entrou como penetra.

(JT, p. 103. Grifo nosso)

Na obra de Aníbal Machado, a solidão está presente no cotidiano de João Ternura, mostrando que a "metrópole é o lugar de coletividades indefinidas, que pode gerar total indiferença de cada indivíduo para com o outro, na vida cotidiana, como traço de autopreservação" (GOMES, 1995, p. 70. Grifo do autor). Nessa perspectiva, indiferença, aversão, estranheza e repulsa marcam as relações do homem citadino, e a grande metrópole passa a ser o lugar em que a pessoa mais se sente solitária. Exemplo dessa situação é quando o protagonista, recém-chegado ao Rio de Janeiro, procura um bar para observar a cidade e encontrar alguém para atenuar sua solidão. Atendido por uma garçonete, que, no cumprimento de seu trabalho, sorri para todos indistintamente, ele retribui o gesto. Alguém que está naquele lugar e sente-se ameaçado o agride fisicamente, dando-lhe um soco. Como João Ternura não entende o código da cidade, não percebe o motivo da agressão. Esse gesto 
pode ser interpretado como uma forma de indiferença, pois, para o indivíduo, os motivos que levam o jovem àquele lugar não importam, e o insulto físico leva a personagem a perceber a cidade como algo hostil. No romance, a indiferença que caracteriza os moradores das metrópoles é traduzida no soco, e marca significativamente a relação do protagonista com a cidade, que é vista por ele como um ser vivente, capaz de (re)agir negativamente sobre os sujeitos, reforçando sua condição de estrangeiro::

DE QUEM O SOCO? — Sentara-se junto à janela. Ainda inseguro de si. A primeira vez entrara num bar. Pediu um chope. Viu-se refletido no espelho. [...] Levantou a cortina. Passava gente.

A cidade funcionando.

Seria mais um, mais alguém no mecanismo dela. Prometido a delícias futuras. Passeou o olhar por outras mesas. Um sujeito que às vezes o encarava com dureza conversava com uma mulher. A mulher servia aos fregueses um sorriso geral e fixo.

Ternura começava também a sorrir para ela quando recebeu um soco. Balançou o corpo e rolou no chão. Ao acordar, não sabia se o soco viera de fora, pela janela, ou do homem que olhava com raiva.

$[\ldots]$

Saiu a perambular. Agora já sem o relógio e sem o pouco dinheiro que trazia. E com uma bofetada a doer mais na alma que na cara.

$[\ldots]$

Aquela bofetada doía-lhe mais pelo anonimato. Não sabia de que, nem de onde viera. Um soco da própria cidade. Do que havia de cruel na alma oculta da cidade...

(JT, p. 104-105-106. Grifo nosso)

Somente três meses após a chegada à cidade é que João Ternura vai à procura de Bernardo, um primo que vive no Rio de Janeiro, para pedir-lhe auxílio na busca de emprego. Talvez a demora para pedir auxílio possa ser interpretada como o desejo que tem de integrarse à metrópole a partir de ações próprias, sem a interferência de um mediador. Mas ao perceber que não consegue vencer as barreiras impostas pelo cotidiano da cidade para sua adaptação ao novo ambiente, ele busca o parente. No entanto, o encontro entre os dois evidencia os contrastes que há entre ambos e a impossibilidade de o outro atender ao pedido do protagonista. O primo, que representa o citadino, está bem-vestido, é desinibido e possui gestos que demonstram sua segurança e integração com o meio ambiente. João Ternura, que, para os padrões da cidade, está mal-vestido, é tímido, inseguro e sente-se inferior diante da figura do interlocutor. No diálogo entre as personagens, observa-se que o primeiro analisa os modos e as roupas do segundo, percebendo a significativa diferença que há entre eles. Essa constatação leva aquele a dar a este uma "receita" para ter sucesso na cidade. No entanto, a fórmula acentua a descaracterização do indivíduo, o anonimato e a impessoalidade, características que a complexidade do meio urbano impõe aos sujeitos e vão de encontro ao que procura o protagonista:

- Sente-se, vamos conversar. Espere aí ... vá até aquele sofá e volte, quero ver como é seu modo de andar. Precisa ficar mais ereto...

Ternura foi e voltou. 
— Visto de costas, o seu jeito desanima. Eu sou franco.

E começou a lição:

- Não vai ser tão fácil como imagina. Primeiro que tudo, você terá que arranjar outro físico, ou melhorar esse que tem. Engorde. Adquira alguns quilos, muitos quilos a mais... Precisa ter presença. Está-se vendo que é tímido. Fui logo notando. Nada bom, isso... Vá metendo os peitos! Mas respeitando sempre as autoridades. Eu me refiro às autoridades, não às leis... Não seja como seu pai que tem mania de escrúpulo. Fale devagar. E com firmeza, mesmo que não tenha nenhuma convicção. Vista-se melhor. E frequiente boas rodas. De preferência, os importantes. Olhe (e fez o gesto de abranger a muitos) esses todos aqui são importantes. E apareça daqui a alguns meses. Mas engorde, primeiro (JT, p. 106)

O encontro, o diálogo e a "receita" que o primo sugere a João Ternura revelam a impossibilidade de o segundo adaptar-se ao ambiente da metrópole, pois precisa, além de modificar sua aparência física, aceitar e apropriar-se de um código ético e moral que lhe é completamente estranho. Ele percebe que as sugestões de Bernardo não podem ser seguidas, pois estão além de seu limite. Outro aspecto que reforça a sua incapacidade de seguir a "receita" do primo está expressa no fragmento ORAÇÃO PARA FICAR GRANDE. Nela o protagonista pede ao "Senhor" para ajudá-lo a mudar sua aparência; no entanto, as "súplicas" além de revelar certa ironia, pois são impossíveis de serem alcançadas evidenciam o quanto a personagem se sente rejeitado na cidade grande:

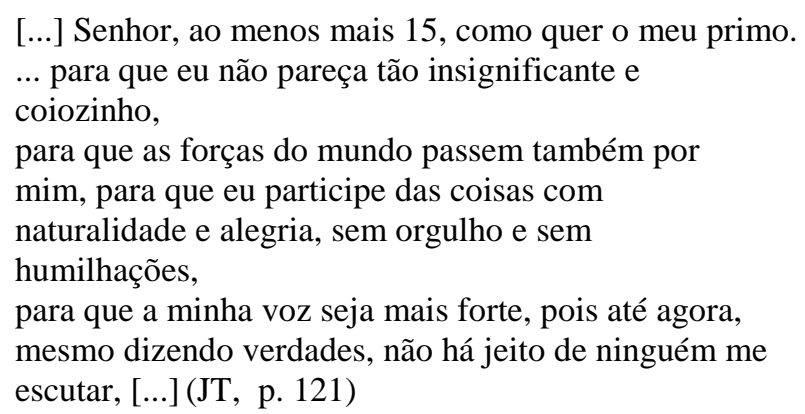

Tempos depois, em carta escrita para o avô, João Ternura informa que não está adaptando-se à cidade e a decisão de não mais procurar o primo, mostrando o distanciamento que há entre os dois na forma de entender o mundo:

[...] Acho que ainda não peguei o jeito de viver aqui. O primo Bernardo não deu certo comigo, é um homem muito importante, só vi ele umas três ou quatro vezes, e não quero ver mais. Tomei horror. (JT, p. 119)

A parte final do romance apresenta situações fantásticas, mostrando o passeio que João Ternura, depois de morto, realiza pela cidade. Do alto, a visão que ele tem do lugar revela as transformações que metrópole apresenta comparada com a do tempo em que nela vivia. Seu olhar é inquiridor e especulativo, pois ao mesmo tempo em que deseja saber quem vive no lugar, ele tenta relacionar as imagens atuais com as lembranças do passado. Suas especulações sobre o que vê e lembra do passado revelam que continua não aceitando o modo de viver do homem metropolitano: "O mundo mudava, e a Ternura não interessava mais viver 
depois que tudo ficara diferente. Para que voltar? [...] Ninguém o reconheceria se ele começasse a caminhar ao lado dos outros" (JT, p.290). Esse pequeno fragmento revela as mudanças da cidade, o desajustes do homem frente a elas e a indiferenças da multidão pelos indivíduos, podendo-se concluir que as constantes modificações das grandes cidades, se não forem feitas considerando o sujeito, levam os metropolitanos a sentirem-se deslocados e estrangeiros dentro de seus mundos, como João Ternura.

O romance de Aníbal Machado, construído em fragmentos não só mostra a história de João Ternura, um anônimo solitário na cidade que buscou atraído pelo desejo de conhecer o mundo, mas revela também que "A cidade moderna é um mundo inenarravelmente concentrado, impossível de ser reconstruído, ou representado, senão por fragmentos, colagens e refração" (GOMES, 1994, p. 142). Sua obra, através da trajetória do protagonista, permite ao leitor um maior entendimento das condições de existência humana nas grandes metrópoles.

\section{Referências}

CUNHA, Fausto. Aníbal Machado entre a poesia e a prosa. In: MACHADO, Aníbal. Seleta em prosa e verso: Introdução, estudos e notas de Fausto Cunha. Rio de Janeiro: José Olympio, 1974.

ANTELO, Raul. Texto, ternura e túmulo. In: Literatura em revista. São Paulo: Ática, 1984.

MACHADO, Aníbal. Cadernos de João. Rio de Janeiro: José Olympio, 2004.

MACHADO, Aníbal. João Ternura. Rio de Janeiro: José Olympio, 2004.

GOMES, Renato Cordeiro. Todas as cidades, a cidade. Rio de Janeiro: Rocco, 1995.

BOLLE, Willi. Fisionomia da metrópole moderna. São: EDUSP, 2000. 